\title{
E.T.A. HOFFMANN EN ÓPERA. \\ SOBRE LA RECEPCIÓN DE SU OBRA EN MÉXICO (1882-1922)
}

\author{
E.T.A. HOFFMANN IN OPERA. \\ ABOUT HIS WORK'S RECEPTION IN MEXICO (1882-1922)
}

Sergio Armando HERNÁNDEZ ROURA

Instituto de Investigaciones Bibliográficas, UNAM ${ }^{1}$

hdez.roura@gmail.com

Resumen: El estreno de Les Contes d'Hoffmann, ópera de Jacques Offenbach, fue central para la difusión de la obra literaria de Hoffmann en México. A partir de la interpretación de las notas, críticas y anuncios aparecidos en la prensa se ha reconstruido el proceso de recepción de esta obra; un ejemplo ilustrativo de la forma en la que esta clase de espectáculos llegó a formar parte del gusto del público y un fenómeno que permite entender cómo se leyó la obra del alemán y dar cuenta del proceso de asimilación de su obra en México.

Palabras clave: Hoffmann. Recepción. México. Offenbach. Transposición.

Abstract: The premiere of Les Contes d'Hoffmann, Jacques Offenbach's opera, was central for the dissemination of Hoffmann's literary work

\footnotetext{
${ }^{1}$ UNAM, Becario del Programa de Becas Posdoctorales en la UNAM, Instituto de Investigaciones Bibliográficas. Asesorado por el Dr. Vicente Quirarte Castañeda.
} 
in Mexico. The reception of this work has been reconstructed from the interpretation of the notes, criticisms and announcements appeared in the press. This process is an illustrative example of the way in which this kind of shows became part of the public's taste; also a phenomenon that allows us to understand how the work of the German was read and its assimilation in Mexico.

Key Words: Hoffmann. Reception. México. Offenbach. Transposition.

Hoffmann siempre antepuso su trabajo como músico al de escritor. Es irónico pensar que este segundo oficio haya sido el que le diera la fama; más aún que en la historia de la difusión de su obra hayan jugado un papel preponderante las adaptaciones de sus obras literarias para llevarlo de regreso al ámbito al que siempre creyó pertenecer, el musical. En el caso particular de México, resultó fundamental el estreno de la ópera de Jacques Offenbach, Les Contes d'Hoffmann, así como la puesta en escena del ballet Coppélia, con música de Léo Delibes; ambas obras dieron a conocer al autor alemán a un público que, si bien aún resultaba restringido, era más amplio que el lector; fenómeno parecido al que ocurre en la actualidad con la adaptación de obras literarias al cine. Así pues, en las siguientes páginas me ocuparé de la recepción de la ópera (cabe mencionarse que en un artículo posterior me referiré al Ballet). A partir de la interpretación de las notas, críticas y anuncios aparecidos en los diarios mostraré la acogida de esta obra, un ejemplo ilustrativo del proceso por el que pasaban los espectáculos operísticos para formar parte del gusto del público y, al mismo tiempo, un testimonio que permite entender cómo se leyó la obra del alemán; es decir, se trata de un fenómeno en el que se ve reflejado el proceso de adopción y asimilación de su obra en México.

Antes de adentrarse en este fenómeno conviene señalar algunos puntos importantes que servirán para entender las críticas a esta ópera. La obra de Offenbach es un ejemplo de hipertextualidad, término que 
González Martínez (2006, 2009) toma de G. Genette para referirse a la relación de transposición entre literatura y música. De acuerdo con lo que expone González Martínez (2006: 168), en el caso de la transposición de esta ópera nos encontraríamos con que el hipotexto original sería los relatos de Hoffmann y su biografía, que daría lugar a un hipertexto (la obra teatral), que a su vez se vuelve hipotexto de la ópera. Al detenerse en las relaciones que unen estos textos es posible observar que, en el tránsito de uno a otro, se han perdido cosas y se han ganado otras. Sin ahondar en el último, que correspondería más al ámbito de la musicología, haré una síntesis de los cambios más evidentes. Me referiré, pues a los procesos transformacionales más evidentes de carácter discursivo y, posteriormente, a los extradiscursivos.

En el primer caso, es posible señalar que a partir de varios cuentos de Hoffmann se ha creado una trama en la que el protagonista de todos ellos es el propio autor. Como veremos más adelante, varias de las opiniones expresadas por la crítica se refirieron a la tergiversación de la biografía del autor y su simplificación. En este caso Hoffmann encarnó el estereotipo del artista bohemio. En una taberna, ubicada frente al teatro donde se lleva a cabo la representación de Don Giovanni de Mozart, el alemán cuenta a un grupo de estudiantes sus fracasos en el plano sentimental; anécdota que se convierte en el origen de sus famosos "Cuentos". En la organización macroestructural (González Martínez, 2009: 268) vemos una simplificación que busca darle unidad a las narraciones; en este caso, el autor es el hilo que las une y las funciones de los personajes se mantienen a lo largo de toda la obra; es decir, en todas ellas el esquema actancial se mantiene, Hoffmann como sujeto; Coppelius-Dr. Miracle-Consejero Lindorf como su oponente; y, finalmente, Olimpia-Antonia-Giulieta-Stella como el objeto inalcanzable.

Si bien la ópera convierte al escritor en un mito romántico al retratarlo como un bohemio irredento asolado por el alcohol, no es menos cierto que la obra permitió que el público de ese momento se familiarizara con algunas de sus narraciones, como "Der Sandmann" ("El hombre de 
arena"), "Rat Crespel" ("El consejero Crespel”) y "Die Abenteuer der Sylvester-Nacht" ("Las aventuras de la noche de San Silvestre"); tres cuentos de marcada raigambre fantástica, junto con algunos personajes procedentes de otras de sus obras, como Pitichinaccio ("Signor Formica"), el consejero Lindorf (Dar Goldene Topf), Klein-Zach o Cinabrio ("Klein Zaches, genannt Zinnober") $)^{2}$ La necesidad de que el autor fuera el protagonista llevó a alterar el sentido de los cuentos; en el caso de "El hombre de arena", el acoso que sufre Natanael desde su infancia y hasta su muerte por Coppelius desaparece y sólo se mantiene el motivo de la muñeca; en "El consejero Crespel", permanece la idea de la fragilidad de la mujer, más que la identificación entre ésta y el famoso violín de Cremona; y en el caso de "Las aventuras de la noche de San Silvestre", si bien se conserva la idea del pacto, se ha eliminado de la historia los acontecimientos que le ocurren al personaje después de entregar su reflejo y las consecuencias ominosas que esto tiene en su vida.

Como señala Castex (1962: 8), Jean-Jacques Ampère fue el primero en destacar que la característica principal de los fenómenos que tenían lugar en las obras de Hoffmann era su dimensión interior y psicológica; a la que se sumaría la ambientación marcadamente cotidiana de sus relatos, lo que dotaba de verosimilitud la "intrusion brutale du mystère dans le cadre de la vie réelle". Al respecto de esta concepción el protagonista de la ópera se presenta como un alcohólico con tendencias a fabular. Si bien este tipo de narradores son recurrentes en la creación de cuentos fantásticos, no hay que olvidar que la historia que enmarca los cuentos pretende ser realista, en tanto que se plantea como origen de las obras de Hoffmann. Su mensaje es contradictorio, por una parte las creaciones se conciben como resultado directo de la biografía del alemán, mientras que por el otro, se exalta la relación entre la vida bohemia y la genialidad. Los sucesos narrados no

\footnotetext{
${ }^{2}$ Pertenecientes a sus libros de cuentos, Nachtstücken (1817), Serapionsbrüder (18191821) y Phantasiestücke in Callots Manier (1814-1815), respectivamente. El último no se presentó en el estreno, ya que el director Carvalho decidió eliminarlo por considerarlo “demasiado extenso y confuso" (Pahlen, 1980: 224).
} 
se cruzan con la realidad y, en este caso, los desvaríos imaginativos son producto del alcohol.

Entre los procesos transformacionales extradiscursivos se puede mencionar que, como se sabe, Offenbach fue vinculado al estilo ligero, más bien entretenido, del vodevil. La obra en cuestión se aleja de la estética frívola a la que había acostumbrado a su público e introduce el lirismo y categorías como lo fantástico, lo grotesco y lo sublime; esto responde a las decisiones que el músico tomó en relación con: “qué es lo que más le interesa del hipotexto, dónde radican sus virtualidades musicales, qué parte del sentido original desea mantener a toda costa y de cuál se puede prescindir, qué pretende que la música aporte a cada momento, qué mecanismos transformacionales prefiere aplicar, etc." (González Martínez, 2006: 185).

En su caso, las respuestas a estas preguntas, giran en torno a la idea de que, frente a su producción anterior, consideró esta su obra maestra. Así pues, su transposición supuso "un estadio hermenéutico y, posteriormente y de manera consecuente, una elaboración del material ofertado que trae consigo una modificación del sentido" (González Martínez, 2006: 181). En su interpretación, además de los conceptos mencionados, la obra tenía la ventaja añadida de mostrar al espectador una serie de retos musicales y vocales, como la representación musical de una muñeca, el planteamiento del canto como metáfora de la vida, la creación de atmósferas oníricas, la indagación musical sobre la muerte y el destino trágico, entre otras. Si bien es cierto que comparado con el drama y con los cuentos originales, "el libreto de la ópera no contiene conceptos tan abstractos, ni sentimientos tan complejos (aunque suelan ser más intensos), ni una riqueza de evocación poética tan amplia. Los personajes, asimismo, hablan con un lenguaje más directo, con una sintaxis lógica y un léxico en el que predominan los valores denotativos" (González Martínez, 2006: 173-174).

En el proceso de transposición, pese a la simplificación que se ocurre en las obras, éstas han ganado en su dimensión musical, como bien afirma González Martínez (2006: 174). 


\section{NOTICIAS PRELIMINARES Y ESTRENO EN MÉXICO}

Si bien es posible encontrar elementos que permiten constatar la presencia de Hoffmann en México desde la década de 18403, gracias a los comentarios diseminados en la prensa periódica y en la obra de algunos autores, se constata el papel destacado que tuvo en el proceso de recepción4 el estreno de la ópera Les Contes d'Hoffmann compuesta por Jacques Offenbach (1819-1880), basada en el libreto de Jules Barbier y Michel Carré5. La prensa mexicana siguió de cerca el proceso de realización de la obra6 y dio cuenta de la famosa tertulia del 18 de mayo de 1879 que

${ }^{3}$ Es importante considerar que su gran difusión fue posterior a su muerte, ocurrida en 1822, comenzando por Francia, donde influyó en autores como Honoré de Balzac, Prosper Mérimée, Alexandre Dumas, George Sand, Théophile Gautier, por citar algunos (Castex, 1962; Teichmann, 1961), y, posteriormente en España, a partir de 1831, cuando circularon sus obras procedentes del francés y estimularon la imaginación de Pedro de Madrazo, José Zorrilla, Antonio Ros de Olano, Gustavo Adolfo Bécquer, Rosalía de Castro y Benito Pérez Galdós, entre otros. Sobre la recepción en España, véase Pérez Gil (1993) y Roas (2002).

${ }^{4} \mathrm{El}$ fenómeno estudiado es parte de un proceso más amplio y complejo en el que están involucradas la circulación de obras en francés y provenientes de España, la traducción, la adaptación, las críticas y la asimilación por parte de los autores mexicanos. El estudio pormenorizado de casa uno de estos aspectos, del que forma parte este trabajo, permite dar cuenta de la adopción de un género o modo literario considerado ajeno a la sensibilidad mexicana dentro de un proceso dinámico, apartado de la imagen monolítica con la que se tiende a contemplar las obras del periodo: "La obra literaria no es un objeto inexistente para sí que ofrezca a cada observador el mismo aspecto en cualquier momento. No es ningún monumento que revele monológicamente su esencia intemporal. Es más bien como una partitura adaptada a la resonancia siempre renovada de la lectura, que redime el texto de la materia de las palabras y lo trae a la existencia actual" (Jauss, 2000: 161). Así pues, los aspectos estudiados permiten dar cuenta del "cambio de horizonte" que se produjo y, sobre todo, la "actualización" (Jauss, 2000: 162) o asimilación de la obra del Hoffmann por los escritores mexicanos.

${ }^{5} \mathrm{La}$ adaptación teatral se presentó en el Théâtre de l'Odeón de París en 1851. Sobre cómo Offenbach obtuvo los derechos para hacer la ópera; véase Pahlen (1980: 216-217).

'Un ejemplo de ello es el texto "Noticias teatrales" (22 de febrero de 1878). La Colonia Española, p. 3: "El Maestro Offenbach estaba en Niza terminando la partitura de una ópera titulada Los cuentos de Hoffmann". 
tuvo lugar en la mansión del compositor ubicada en el Boulevard des Capuccines, en la que presentó a sus invitados los avances y se ganó la aprobación de Léon Carvalho, rector de la Ópera de París, y Franz von Jauner, jefe en ese momento de la Ópera Imperial de Viena, quienes no dudaron en presentarla en cuanto estuviera acabada. Le Trait d'Union del 29 de junio de 1879 dio a conocer el testimonio del escritor francés Frédéric Gaillardet, en cuya crónica señala:

On ne s'est pas moins donné de peine pour assister à une representation dans le salon de Jacques Offenbach, des fragments d'une opéra fantastique qu'il a composé sur les fameux contes de Hoffmann, en collaboration avec MM. Jules Barbier et Michel Carré pour les paroles. Autant qu'on en peut juger par une audition partielle, ce sera un des æuvres capitales d'Offenbach. Il est sorti de l'opérette pour entrer dans la veritable opéra comique. Cela s'explique par ce fait qu'il avait destiné cette pièce au Théâtre-Lyrique, et que ce théâtre étant fermé, il l'a cedée à M. Jauner, directeur de l'Opéra impérial de Vienne. Mais Offenbach a voulu la présenter d'abord à ses amis de France "pour prendre congé", comme on dit. Heureusement, ce petit opéra nous reviedra bientôt, car le Théâtre-Lyrique va se rouvrir, et il sera, pendant trois mois, à partir du ler fevrier 1880, théâtre italien, avec la Pati et Nicolini qui on contracté, dit-on, un engagement serieux. Gaillardet, F. (29 de junio de 1879). Correspondence Gallardet. Le Trait d'Union, pp. 1-2.7

Del mismo modo que estuvo informado sobre el proceso creativo, el público mexicano se enteró de la muerte del compositor, ocurrida el

${ }^{7}$ En las transcripciones de textos en francés que se presentan en este artículo se ha respetado la ortografía del original. Únicamente se señala en algunos casos las erratas en nombres propios. 
5 de octubre de 1880 a los 61 años, así como del carácter inconcluso de la que se consideró su obra maestra; cuya orquestación quedó en manos de Ernest Guiraud ${ }^{8}$. C.L. se encargó de transmitir la información en una nota luctuosa aparecida en La Patria, acompañada de una semblanza que destaca el carácter de "enfant terrible" del compositor, su profunda observación y mordacidad como caricaturista, así como su fecundidad y originalidad. Además de señalar que en ese momento la obra se presentaba en la Opéra-Comique, el autor asegura que se trataba de "la ópera cómica que más quería su autor. Siempre estaba hablando de ella. Con frecuencia le veían sus amigos sentarse al piano y sus dedos retorcidos por la gota, tocar algunos trozos escogidos". C.L. (10 de noviembre 1880). Muerte de Offenbach. La Patria, p. 2.

En efecto, Les Contes d'Hoffmann se había estrenado en la OpéraComique el 10 de febrero de 1881, en una temporada, de acuerdo con Pahlen (1980: 229), en la que se presentó "no menos de cien veces". Al respecto de los preparativos apareció una nota el 16 de febrero, en la que se anunció su próximo estreno en México:

Desde que la ópera cómica ha representado "El Amor Médico", M. Carralho [sic] se ha consagrado enteramente a los ensayos generales de "Los Cuentos de Hoffmann", que cree representar en la segunda quincena de este mes (enero).

M. Ernest Guirano [sic] ha terminado su trabajo de orquestación y M. Jules Barbier ha dado la última mano a las modificaciones que los estudios de escena han indicado. Los intérpretes saben sus papeles, y son, según parece, de los más notables. Las decoraciones se ajustan y los trues van a entrar en repetición. En cuanto a la orquesta y a los coros, M.M. Danbé [sic] y Carré responden de ellos.

\footnotetext{
${ }^{8}$ Sobre los problemas que ha supuesto este hecho, Pahlen (1980: 220-234).
} 
Así pues, dentro de poco tendremos la gran obra póstuma de Jacques Offenbach. Los Cuentos de Hoffmann. (16 de febrero 1881). La Patria, p. 3.

Diez meses después del estreno parisino, se produjo el espectáculo en la capital austriaca traducida al alemán en el Ringtheater el 7 de diciembre de 1881. Desafortunadamente durante la segunda función, es decir, la del 8 de diciembre, se produjo el famoso incendio que le diera su fama de obra maldita9 . La sección Sucesos del día de La Patria dio la nota del siniestro: "Se confirma el incendio del teatro 'Ring', en Viena, durante la representación de 'Los cuentos de Hoffmann'. Perecieron mil personas". Horrible catástrofe. (20 de enero de 1882). La Patria, p. 2. Una crónica vívida y detallada del siniestro, aunque desde París (!), puede leerse en Herrera, A. (1 de febrero de 1882). Revista política europea. El Siglo XIX, p. 1. El autor se encargó de difundir las medidas filantrópicas de solidaridad de algunas de las capitales europeas más importantes, como París, Madrid, Berlín, Bruselas y Roma.

Este desafortunado evento no mermó la expectación en México y su estreno se anunció con anticipación mientras que se preparaba el terreno con notas cuya finalidad era predisponer el ánimo del espectador. Resulta elocuente a este respecto el seguimiento dado a la Compañía de Mauricio Grau. Un mes antes de su arribo a la capital mexicana se tuvieron noticias en carta desde la Habana dirigida a Vicente García Torres, director de El Monitor Republicano. Don Clarencio (18 de noviembre 1882). Correspondencia particular del "Monitor Republicano". El Monitor Republicano, p. 1. El corresponsal dio cuenta del éxito de la compañía de Grau en Cuba, que contaba con la presencia de dos estrellas, el tenor Victor Capoul y la tiple Louise Théo. El corresponsal escribe sobre el estreno de la obra póstuma de Offenbach en la capital cubana ocurrido el

\footnotetext{
${ }^{9}$ Esto pese a que en esta puesta en escena no se tocó el aria de la "Barcarola" y que ocurrió justo antes de que comenzara la obra.
} 
3 de noviembre, y de su segunda función, en la que se presentó Madame l'Archiduc, obra del mismo músico. Por lo que se puede observar en su comentario del libreto, el montaje presentado en la capital cubana siguió la puesta en escena francesa, en la que se prescindió del acto dedicado a "El reflejo perdido". En el texto se resalta el carácter marcadamente fantástico de su fuente de inspiración: "Offenbach buscó un libro extraño, fantástico, que había causado época por la originalidad de su argumento, para entrar en los campos de la música seria y sublime, que no le estaban vedados y en que podía brillar, como lo ha demostrado esa obra". Precisamente el carácter etéreo al que se refiere marcó una diferencia con respecto a los trabajos anteriores del compositor, identificados por su ligereza y frivolidad ${ }^{10}$.

E1 25 de noviembre El Nacional publicó en la sección Diversiones públicas toda la información referente a la temporada 1882-1883 del "Gran Teatro Nacional" que daría comienzo ese 13 de diciembre ${ }^{11}$. Gran Teatro Nacional. (25 de noviembre de 1882). El Nacional, p. 3. Como asegura la nota, el público mexicano tendría la oportunidad de disfrutar una muestra del "arte lírico francés", entre cuyas obras figuraba Los cuentos de Hoffman [sic]. Para la puesta en escena en México, Grau refundiría la compañía que había ido a Cuba junto con la que se presentó en Nueva York. La extensa nota daba cuenta del elenco, el repertorio y las condiciones de abono.

Varias semanas después, la llegada a tierras mexicanas de la Compañía se anunció en "Miscelánea". (10 de diciembre de 1882). La Voz de México, p. 3: "LA COMPAÑÍA DE ÓPERA FRANCESA llegará hoy a Veracruz en el vapor 'Nueva York'. Allí dará como hemos dicho tres funciones en los días 11, 12 y 13. Se nos dice que en México se estrenará con los 'Cuentos de Hoffman [sic]'". Como si de contar los minutos se tratara, El Centinela Español del 13 de diciembre publicó en su sección

\footnotetext{
${ }^{10}$ Para observar la fama de Offenbach a este respecto es posible consultar a Ramos Smith (2013: 59-78) y Bidault de la Calle (2002).

${ }^{11}$ La temporada terminó el 4 de febrero con Le Pré aux clercs de Ferdinand Hérold (Olavarria y Ferrari, 1961: 1063).
} 
Gacetilla el siguiente texto:

El diez en la noche desembarcó en Veracruz toda la lucida compañia que trae Mr. Grau. Anteayer[,] ayer y hoy ha dado funciones en la ciudad Heroica, de donde saldrá mañana en tren especial con dirección a ésta: aqui se estrenará el 15 con "Los cuentos de Hoffman [sic]". Según un telegrama que acabamos de recibir de Veracruz, su presentación alli ha causado un furor nunca visto, lo cual no nos extraña, dada la importancia del numeroso y lucido personal que compone la troupe Grau. Ópera francesa. (13 de diciembre de 1882). El Centinela Español, p. 2.

Se siguió el camino de la compañía hasta su llegada a la ciudad, como se puede constatar en la publicación del 15 de diciembre, fecha del estreno, aparecido en La Patria, que anuncia el evento de esa noche:

Ayer en la tarde llegó a esta capital la alegre compañia de M. Grau, a quien felicitamos desde ahora por la magnifica acogida que se le prepara, pues el entusiasmo que notamos en nuestro público, no conoce límites.

Hoy en la noche tendrá lugar la primera función de abono del turno impar, poniéndose en escena, por primera vez, la sublime ópera seria en tres actos y cuatro cuadros, última producción del célebre Offenbach, intitulada "Les Contes á Hoffmann [sic]". Al Nacional, para tomar nuestras respectivas localidades, queridos lectores. No hay que dormirse. La Troupe francesa. (15 de diciembre de 1882). La Patria, p. 3.

En la misma página se promueve esa función, asegurando que además de ser la mejor obra del compositor, el público mexicano se 
encontraría frente a una producción con más de 200 representaciones en la Opéra-Comique ${ }^{12}$. Ese mismo día Le Trait d'Union publicó un artículo de autor anónimo, un texto fundamental para la historia de la recepción crítica de la obra de Hoffmann: Les Contes d'Hoffmann. (15 de diciembre de 1882). Le Trait d'Union, p. 2. Su autor, quien escribe en francés, considera pertinente introducir al público al acontecimiento que tendría lugar esa noche en el Gran Teatro Nacional; para ello, le dedicó un extenso artículo dividido en tres partes en las que se refiere al autor alemán, al libreto y finalmente a la música. En la primera sección, titulada "Notes sur Hoffmann", el autor presenta algunos apuntes dedicados a la obra del alemán, en los que asegura que su introducción en Francia se debió a la edición de "Loewe-Weymar" $[\text { sic }]^{13}$, aunque reconoce sus limitaciones, su carácter imperfecto y fragmentario ${ }^{14}$. Para él, lamentablemente la obra de este autor no había sido considerada por su valor literario, sino a partir de su persona; por lo que, a diferencia de sus detractores, de los que destaca a Walter $\mathrm{Scott}^{15}$, el autor de este texto destaca su imaginación, así como

\footnotetext{
${ }^{12}$ También aparece anunciada en Diversiones públicas. (15 de diciembre de 1882). La Oposición Radical, p. 3. En el folletín Reyer E. (20 de enero de 1886) Revue Musicale de l'année 1885. Le Trait d'Union, pp. 1-2; fue publicada una crítica que parece desmentir esta información sobre el número de representaciones (p. 2). Tras hacer una reseña de las óperas Tabarin, Faust, Le Cid, Les Deux Pigeons, el autor señala que la ópera de Offenbach se había presentado 115 veces. El texto se publicó originalmente en Revue Musicale. (27 de diciembre de 1885). Journal de Débats Politiques et Littéraires, pp. 1-2. ${ }^{13}$ Se trata de la edición de François Adolphe Loève-Veimars de Oeuvres complètes que comenzó en 1829 y terminó en 1836. Como se sabe, el proceso de recepción en Francia inició mucho antes de la publicación de esta obra, es decir, en 1828. Véase Castex (1962), Teichmann (1961).

${ }^{14}$ Esto ha sido constatado por Pérez Gil (1993).

${ }^{15}$ Scott, W. (julio-noviembre, 1827). On the Supernatural in Fictitious Composition; and particularly on the Works of Ernest Theodore William Hoffman[n]. Foreign Quarterly Review, pp. 60-98. El autor opone su forma de entender el uso de lo sobrenatural frente al del alemán, a quien se encarga de denostar, al presentarlo como un ser consumido por el alcohol; si bien se trataba de un hombre de "rare talent", esto presenta serios inconvenientes: "but unhappily of a hypochondriac and whimsical disposition, which carried him to extremes in all his undertakings; so his music became capricious, - - his drawings caricatures, - and his tales, as he himself termed them, fantastic extravagances" (p. 74). Otro fragmento muy elocuente sobre esta mirada desfavorecedora: "But that which is to
} 
la asombrosa capacidad del escritor alemán para llevar una doble vida, dedicada al mismo tiempo a las leyes y al arte. En su opinión, Hoffmann no sólo había sido "estigmatizado calumniosamente" por el escocés, sino también por Barbier y Carré, autores del libreto, quienes en su trama se encargaban de difundir un prejuicio, al presentar al autor como borracho y fracasado. Por el contrario, encuentra la justificación de su carácter bohemio y los altibajos de su personalidad en algunos sucesos desafortunados de su vida:

Cette existence de hasards, avec ses hauts et ses bas, ses espérances dorées et ses réalités accablantes, peut bien justifier la qualification de bohême donne à Hoffmann par Walter Scott, mais elle implique une variété de ressources, une présence d'esprit de tous les instants, qui montre dans Hoffmann l'énergie, la volonté réfléchie, la force morale de l'homme capable de dominer la vie et de soumettre son imagination à ses besoins, loin de se laisser commander par elle.

Es consciente de que el término "cuentos fantásticos" dado a las obras narrativas de Hoffmann es de invención francesa y demuestra conocer las tres recopilaciones de sus cuentos. Encuentra de particular

the person whose mind is in a healthy state, but a transitory though disagreeable feeling, becomes an actual disease in such minds as that of Hoffmann, which are doomed to experience in too vivid perceptions in alternate excess, but far most often and longest in that which is painful, - the influence of an over-excited fancy. It is minds so conformed to which Burton applies his abstract of Melancholy, giving alternately the joys and the pains which arise from the influence of the imagination" (p. 79). Al respecto de la nueva tendencia que representa Hoffmann, el escocés afirma: "This may be called the FANTASTIC mode of writing, in which the most wild and unbounded licence is given to an irregular fancy, and all species of combination however ludicrous or however shocking, are attempted and executed without scruple" (p. 72). Este ataque fue publicado en Francia $\mathrm{y}$, contrariamente a lo esperado, generó una abierta animadversión en contra Scott en defensa de Hoffmann por figuras como Loève-Veimars, Jean-Jacques Ampère, Duvergier de Hauranne, Charles Nodier, Th. Gautier, sólo por mencionar a los más importantes. Esto en detrimento de la popularidad del inglés (Castex, 1962: 51). 
interés el posicionamiento del autor con respecto a la idea de realidad:

Ce dernier titre [Fantaisies à la manière de Callot] peint l'homme et l'artiste. Hoffmann est, en effet, un observateur exact, patient et sagace de la réalité, qu'il interprète à la manière d'un Callot, d'un Rembrandt, d'un Goya, en lui faisant rendre tout ce qu'elle peut donner de pittoresque, tout ce qu'elle peut contenir de terreur vrai, grâce à une interprétation singulièrement pénétrante, à une étude psychique des plus délicates, et au contraste savant des lumières et des ombres.

Finalmente, el artículo se detiene en la partitura; encuentra que la obra se divide en dos partes diferenciadas, una de ópera pura y la otra de ópera cómica. Al escribir sobre la música, demuestra estar al tanto del trabajo de Léo Delibes, quien a partir de una reinterpretación del cuento “Der Sandmann", realizó el ballet Coppélia, que se estrenó en 1870. El texto concluye con una reflexión sobre el éxito, señalando que: "En résumé, si la musique des Contes d'Hoffmann ne diminue en rien la grande reputation du regretté Offenbach, el ne la grandit pas d'un pouce. On jugera ce soir".

En los días posteriores al estreno, los diarios se encargaron de difundir las reacciones del público ${ }^{16}$. En lo que todos coinciden es en una desafortunada recepción más bien fría; reconocen el trabajo realizado, la puesta en escena y las interpretaciones, pero coinciden en que la obra no respondió a lo que se esperaba de Offenbach. Así opina Iza, Luis G. (17 de

\footnotetext{
${ }^{16} \mathrm{El}$ evento no aparece mencionado por Mañón (2009), quien salta de 1882 a 1885 sin mencionar la presencia de la compañía de Grau; Reyes de la Maza (1964: 27) tampoco le da gran importancia, ya que aunque señala que es "la última y quizá más bella opereta de Offenbach", no da cuenta de la ausencia de la Barcarola, que no se interpretó en esa ocasión: “Apenas si la 'Barcarola', el trozo musical cursilón que todavía es preferido por los que presumen de gusto por la 'música clásica', arrancó aplausos; el resto pasó inadvertido y aun con enojo hacia Grau por haber elegido aquella producción para el debut de la compañía”.
} 
diciembre 1882). Revista de la semana. La Patria, p. 1, en la que destaca el acierto de la partitura, debida en su mayor parte a la inspiración del compositor; sin embargo, afirma que la reacción del público no resultó ser el de una obra tan esperada. En su opinión, se debe al carácter híbrido y a la falta de unidad que esto supone: "Me causa pena decirlo: la pieza en general, no fue del agrado del público; notándose desde luego que esa obra no está escrita por una misma mano; de allí la promiscuidad del género bufo y serio: la música francesa, chispeante, alegre, festiva, en combinación con la melodía suave y sentimental de la italiana".

Pese a ello, destaca las interpretaciones de las cantantes, las señoras Marie Derivis y Anaïs Privat, que en su opinión "fueron acaso las que causaran sensación en el ánimo del público, desempeñando admirablemente la primera [es decir, la Derivis], su doble papel de muñeca y de mujer, conquistando nutridos aplausos: el público la hizo una verdadera ovación"; y la segunda, como Antonia, “en su pequeño papel de una voz, [que] logró cautivar con la suya, vibrante y melodiosa". A su comentario sobre el tenor vincula su explicación de la reacción desfavorable, aunque no deja de celebrar la presencia de ese tipo de espectáculos del país:

En cuanto al tenor, es necesario reservarse para juzgarle: un artista no puede ser comprendido ni desarrollar sus facultades en la primera representación; máxime, cuando se supone que, la fatiga del viaje y el temor de un público desconocido, no les permiten revelar, hacer patentes todas sus facultades.

Así se comprende por qué se le recibió con alguna frialdad. Además, como la obra que se puso en escena, no ofrece grande interés, no hay en ella pasages [sic] ni situaciones que puedan hacer brillar dignamente las dotes de un artista.

De todas maneras, y a reserva de hacer más estensos [sic] estos apuntes en el curso de la semana, debe felicitarse a nuestra sociedad por contar en su elegante teatro con una Compañia de Ópera como la que ha traído el Sr. Grau: tanto más, cuanto que 
aún faltan por conocer las verdaderas notabilidades que componen el cuadro de aquella Compañía, la que, lo repetimos, es digna de la cultura e ilustración de la sociedad mexicana.

En “Charla de los domingos" publicada por El Monitor Republicano de la misma fecha, después de referirse a la época de posadas, a una tertulia en el Hipódromo Alemán en La Piedad y a la festividad de la Virgen de Guadalupe, Enrique Chávarri, con el pseudónimo de Juvenal, dedica algunos párrafos al estreno de Les Contes d'Hoffmann. Chavarri. E. (17 de diciembre 1992). Charla de los domingos. El Monitor Republicano, p. 1. El autor coincide la opinión de que fue un error por parte del empresario haber elegido esa obra para el debut. Sobre el libreto, asume que se trata de una obra biográfica, "un digno recuerdo de la vida del ilustre cantor alemán; del que vivió delirando entre las grandes inspiraciones de la poesía, de la música, de la pintura". Se percibe en sus opiniones que compartió la visión estereotipada del personaje, ya que en su opinión el libreto "representa[ba] al poeta en uno de esos momentos en que en medio de la bacanal, iba a ahogar sus recuerdos y sus decepciones en el fondo de una copa". El final, en este caso, era más bien desolador: "Hoffmann no puede continuar, está ebrio, y cae desplomado, en el momento en que en la taberna se presenta la única mujer que le había amado con locura”. En su interpretación, la verdadera tragedia es el alcoholismo. Aunque esto concuerda con uno de los finales "tradicionales", como señala Pahlen (1980: 254), existen elementos convincentes que apuntan en otra dirección, en la que el fracaso material más bien se ve premiado por el encuentro con la musa. Quizá sea exagerado asumir, como Chávarri, que Stella amara "con locura" al protagonista dado que no muestra demasiada oposición al irse con el Consejero Lindorf.

Pese a reconocer el talento de los cantantes, la Derivis y Maire en el protagónico, Chávarri señala que la obra no resultó de su agrado, ya que para él, "la música de la ópera no revela su genio, ni la musa de Offenbach; tiene trozos bellísimos, pero en lo general es escasa y monótona”. Se 
explica la desfavorable recepción de la obra de la siguiente manera:

Es lástima, en verdad, que el estreno de la compañia estuviese frío, debido a la mala elección de la obra; sin embargo, hemos vuelto a ver aquella escena llena de movimiento y de vida, aquellas caras, que no son por cierto de autómatas como las de nuestros coristas, aquellos trajes irreprochables y aun se estrenó una nueva decoración bastante perfecta.

En el texto publicado en El Siglo XIX el 18 de diciembre, Mauricio Grau es visto como el general de un ejército que despliega "un cuerpo de exploradores" y descubre que su "acción preliminar" ha resultado un fracaso, ya que Los cuentos de Hoffmann "no tuvieron el don de seducir a nuestros diletanti" (Citado en Sosa, 2010: 192). Pese a que las interpretaciones le parecieron buenas, el autor de la nota expresa su opinión desfavorable, en la que evidentemente desconoce la procedencia de los cuentos:

El poema sin hilación y sin interés, es una serie de escenas confusas en que van desfilándolos personajes fantásticos de los Hermanos de Serapión, y en que Hoffmann, que fue un gran músico, un buen pintor, un notable poeta y un distinguido jurisconsulto, aparece bajo la figura antipática de un calavera vulgar que se enamora sucesivamente de una cantatriz que le engaña, de una tísica que muere cantando como la Traviata, y de una mujer autómata que, al desbaratarse, desbarata sus inverosímiles ilusiones (Citado en Sosa, 2010: 192).

Le Trait d'Union concuerda con las mismas opiniones: La presse et la Compagnie Grau. (19 de diciembre de 1882). Le Trait d'Union, p. 3. Si bien no considera lo ocurrido expresamente un fracaso, señala el 
evidente contraste de las reacciones del público con respecto al triunfo indiscutible de Mignon $^{17}$, con música de Ambroise Thomas y libreto en francés de Barbier y Carré, que consideró un delirio: “Quel succès!... Quelles ovations!... La Privat, la Leroux, Capoul et Maugé, sourtout les deux premiers rôles, peuvent avoir, dans le cours de leur carrière artistique, reçu des aplaudissements et des bravos en aussi grand nombre, nous n'en doutons pas, mais plus nombreux, plus chaleureux et plus mérités, jamais".

El autor del artículo, Los cuentos de Hoffmann (21 de diciembre de 1882). El Nacional, p. 2, con motivo de la segunda función, ocurrida la noche del lunes, da una explicación diferente a las opiniones adversas, con respecto a una ópera que había sido un éxito rotundo en París: se debía a la ignorancia de los mexicanos en materia de literatura alemana. El autor se remonta a la historia del libreto que dio lugar a la ópera y al argumento. Al referirse a este último, resulta una incógnita que aluda a la aparición del personaje de Julieta, debido a que no formó parte de esa puesta en escena de la obra de Offenbach porque pertenecía al fragmento de "El reflejo perdido"; sin embargo, parece que sólo se trataba de una mención que ocurría en la taberna en la que se lleva a cabo el último acto:

En el cuarto acto volvemos a encontrar a Hoffmann en la taberna, rodeado de sus amigos. Termina su narración contando sus amores con la tercera mujer que fue dueña de su corazón. Esta era Julieta, la cortesana sin alma que no deja de sí más que la duda y la desesperación, que marchita, corrompe y envilece cuanto toca.

Hoffmann analiza los tres elementos: Olimpia, Antonia y Julieta, $y$ cree ver la sintesis en Stella; así es cuando ésta se presenta, concluida que fue la representación de D. Juan, el poeta la rechaza. Stella, para Hoffmann, es la jeune fille, l'artiste et la

${ }^{17}$ Mignon se presentó en el Gran Teatro Nacional el 5 y 13 de enero de 1881 (Sosa, 2010: 185). 
courtisane.

La actriz, despechada, se aleja apoyada en el brazo del consejero Lendorff [sic], autor de toda la trama.

Como se puede observar en este fragmento, el autor destaca un tema fundamental de la obra de Hoffmann: el miedo a la pérdida de la voluntad; un temor que persiste en las tres historias, en las que el escritor alemán, como también sus personajes, es víctima de fuerzas oscuras que lo sobrepasan, encarnaciones de "el principio del mal" (Pahlen, 19080: 254), personificadas por Coppelius-Dr. Miracle-Consejero Lindorf.

\section{M. GUTIÉRREZ NÁJERA Y EL ESTRENO}

El momento culminante de estas críticas fue la intervención de Manuel Gutiérrez Nájera, El Duque Job, quien le dedicó una extensa crónica al acontecimiento; Gutiérrez Nájera, M. (21 de diciembre de 1882). Los cuentos de Hoffmann. La Libertad, p. 2. Además del valor poético de su estilo, al que tenía acostumbrados a sus lectores, el autor legó un testimonio del gusto estético y del conocimiento que circulaba sobre el autor. El texto inicia con una cita perteneciente a Théophile Gautier, en la que el autor de Émaux et Camées afirma que la popularidad del alemán era mayor en Francia que en su propio país, aun cuando advierte que el "francés no es dado a fantasías por su naturaleza"18. Gutiérrez Nájera concuerda con esta idea: "la media luz, tan necesaria a lo fantástico, no existe en Francia ni en el pensamiento, ni en la lengua ni en las casas. Los cuentos de Hoffmann son incompatibles con nuestros pensamientos

\footnotetext{
${ }^{18}$ Este fragmento pertenece a Gautier, T. (14 de agosto de 1836). Contes d'Hoffmann. Chronique de Paris, pp. 441-447. El texto, publicado sin la parte final en su primera versión, apareció con el título de "Études littéraires. Hoffmann" en Musée des Familles (1841) y en 1874 en la edición de Charpentier de Contes d'Hoffmann. El texto completo se encuentra en Souvenirs de théâtre, d'art et de critique de Théophile Gautier (1883) publicada en París por Charpentier (Spoelberch de Lovenjoul, 1968: 93).
} 
volterianos, nuestras lámparas de cristal y nuestras grandes ventanas"19.

Nada afecto a las obras de Offenbach, El Duque Job señala que la obra estrenada fue resultado de la exploración de nuevos caminos por parte del compositor, ya que "los cascabeles de Offenbach dejaron de aturdir los oídos luego que perdieron los granos de plomo de la actualidad". Ubica Les Contes d'Hoffmann en una etapa en la que sus trabajos "se diferencian de sus primeras obras bufas y se acercan a la buena música francesa". Para él, en ninguna de sus composiciones anteriores "es tan visible y clara la transmutación"; algo que, por lo visto en las opiniones difundidas, no pasó desapercibido para el público "lego", quien no se encontró con lo que estaba acostumbrado a esperar de él, y que, precisamente por eso, consideró que poseía "una música pesada". Contrario a esta opinión, Gutiérrez Nájera percibió en esta obra, la ligereza y sobre todo el interés del compositor por evitar la monotonía.

El “melodrama” escrito por Barbier y Carré ganó su desaprobación, aunque no deja de reconocer la originalidad de éstos al ubicar las acciones en la taberna:

Yo no os lo aconsejo: para admirar una obra tonta y descosida, basta con el libreto de la ópera. Tal parece que Barbier tiene el propósito de hacer daño y mala obra a los autores alemanes. En el libreto de Mignon afea y degrada a la heroina de Wilhelm Meister. El libreto de Los cuentos de Hoffmann ridiculiza al ex-

\footnotetext{
${ }^{19}$ Esta opinión al respecto de la literatura fantástica, con algunos resabios de las ideas de Hippolyte Taine, persistió incluso a principios del siglo XX, como se ve en el texto de Poulat, J. (22 de mayo de 1910). Para los que escriben cuentos. El Imparcial, p. 11. Este artículo funciona como una poética del cuento, que además deja ver la popularidad de la narrativa breve en ese momento. En él persiste la idea de que el gusto por ciertos temas y tratamientos, en este caso lo macabro y lo fantástico, son más apropiados para la sensibilidad de otros pueblos: "Los ingleses y americanos, más ingenuos que los latinos, siguen las huellas de Edgard Poe y cultivan la narración extraordinaria, sobrenatural, cargada de horrores. Tienen obras notables de observación y análisis, pero abundan particularmente las de hechos extrahumanos y fenómenos inexplicables".
} 
travagante narrador, y entra a saco en la cuidad de sus leyendas, violando a las doncellas y afrentando las canas de los viejos.

En su opinión, "los libretistas han hilvanado con un hilo burdo y grueso" tres de los cuentos: "Maese Coppelius", "El violín de Cremona" y "Don Juan", títulos que dejan ver que el Duque Job tenía conocimiento de ellos mediante alguna edición ya sea francesa o en traducción procedente de esa lengua. Otro aspecto importante que confirma esto es que Gutiérrez Nájera denominar la obra como "Los cuentos fantásticos de Hoffmann", lo que permite comprobar que conocía y estaba al tanto de la denominación que le había dado el filólogo Jean-Jacques Ampère a la narrativa hoffmaniana.

El autor encuentra trágica y de una verdad profunda la metáfora del enamoramiento de una muñeca; para él, todos los hombres se pueden identificar con ella, porque las mujeres "son muñecas conscientes; tienen uñas; chupan la sangre, como los vampiros, y matan con su amor, como el manzanillo con su sombra". Así pues, considera que las mujeres de Hoffmann son "símbolos dramáticos": "Olimpia es la querida que nos engaña, y Antonia la novia que se nos muere". Con respecto a Stella, reconoce que no es un símbolo, aunque representa el opuesto de las otras dos, es decir, la vulgaridad del mundo cotidiano. Capta de esta manera uno de los puntos más importantes de la concepción del arte de Hoffmann, quien en todo momento trataba de evadirse del mundo cotidiano. En su opinión esta mujer en particular "no ofrecía tan vasto campo a las divagaciones del poeta, ni del músico. Sin embargo, Hoffmann debía rechazarla, no porque se asemejase a las infortunadas heroínas de su amor, sino porque Stella, en cierto modo, pertenecía a todos, y esto sublevaba los sentidos nobles del enamorado". Sin embargo, aunque le da otra interpretación a este hecho, en la cual refleja una percepción muy parecida a la de Chavarri sobre el desenlace del drama: "Volvemos a la taberna, en donde los bebedores de cerveza cantan en alegre coro. Stella vuelve del teatro y habla de amor a Hoffmann, pero el poeta la rechaza; no quiere amar de nuevo; está maldito: la única querida que no muere y que no engaña es... la cerveza". 
Para el Duque Job la obra estrenada en el Gran Teatro Nacional no le hacía justicia al alemán; "ni los autores del libreto, ni Offenbach, supieron sacar provecho de este asunto", ya que considera que el compositor "quiso probarnos que podía hacer una grande ópera, y no lo consiguió”. Aunque el conjunto no le parece prodigioso, expresa su agrado por algunos pasajes:

Hay en ellos [Los cuentos de Hoffmann] algunas páginas preciosas, dignas de Auber y de Bö̈eldieu. Citaré en el primer acto, el coro de estudiantes; en el segundo, las coplas de la muñeca; y en el tercero, todo. Empieza este acto por la romanza deliciosa que Antonia canta al piano, llena de melancólica ternura; viene luego una barcarola a dos voces, deliciosamente escrita, en seguida el dúo de amor, y por último el gran trío, de poderoso arranque dramático.

En cuanto al trabajo de los cantantes, considera excelente la interpretación; en particular el trabajo de Derivis en el papel de Coppelia. Al respecto expresa que "cualquiera la habría tomado por una mujer de carne y hueso. Canta como Mademoiselle Privat y baila como Rosita Mauri”. Destaca la interpretación de la mezzosoprano y concuerda con los elogios tributados por los diarios parisienses;

su voz de gran volumen y perfectamente modelada llena bien el teatro. La inteligente artista tiene además un buen talento escénico, del que dio pruebas bastantes en el papel de la muñeca. Su cuerpo toma la rigidez de los autómatas. Sus movimientos pueden medirse con un compás, y nunca exceden de una línea fija. Cuando canta, las notas, más que brotar de una garganta humana parecen salir del angosto cañuto de la flauta. 
Asimismo sobre Alice Betty, quien hizo el papel de Nicklausse, el joven amigo del protagonista, señala que "lleva con garbo y desparpajo el traje de hombre, que le sienta a las mil maravillas. Viéndola así, cualquiera cambiaría de sexo para amarla"; de Maire, quien interpretó al escritor alemán, afirma que "tiene una voz de tenor fresca y lozana. No pudo tenerla así Hoffmann que fumaba mucho y bebía toneles de cerveza”. Finalmente, del señor Maugé, que encarnó a los siniestros antagonistas, dice "nada puede decirse, porque todo es poco. Es un artista consumado: la perla masculina de la compañía".

Aunque reconoce el trabajo del compositor, señala que "no impunemente se atraviesa por el fácil sendero de los bufos", ya que "a trechos, en el airoso corto de unas coplas, en el alegre giro de una melodía, suenan los cascabeles de Offenbach".

Como se puede observar en las críticas de uno de los escritores más importantes de la época, el autor era consciente de que las obras de Hoffmann eran más complejas de lo que la ópera dejaba ver, y sin embargo reconoce que algunas de sus verdades etéreas y nocturnas se percibían en la obra.

\section{LA SOMBRA DE HOFFMANN}

En su "Revista de teatros". (24 de diciembre de 1882). El Centinela Español, p. 2, tras celebrar la variedad de diversiones de ese invierno y referirse a los espectáculos que se presentaban en el Circo Orrin y el Teatro Arbeu, Pablo comparte con sus lectores algunos comentarios sobre la ópera de Offenbach. Para ello, pone a su público en antecedentes al respecto de la labor de los cantantes. Lamenta los pocos aplausos. Celebra el trabajo de Capoul quien al parecer no encantó e intenta justificar esta situación. Precisamente, en un intento por influir en la opinión del público y revertir los efectos de lo que se consideró un fracaso, publicó un texto escrito por el propio Víctor Capoul, traducido de Le Figaro. Capoul. V. (27 de diciembre de 1882). Mi viaje a América. El Nacional, p. 1. El texto 
refiere en sus últimas líneas el éxito rotundo de la ópera de Offenbach en EE.UU.:

Voy a concluir con una buena noticia. Los Cuentos de Hoffmann se recibieron en Nueva York con el mismo entusiasmo que en París. Mlle. Derivis [sic], una cantatriz de primer orden y de una voz magnifica, estuvo encantadora en el papel de la muñeca y el Sr. Maire [,] un tenor cuyo porvenir está asegurado en París, compartió justamente las ovaciones de su graciosa compañera. Merece una mención especial el Sr. Maugé, que compuso y cantó el papel del doctor Miracle con un arte y una maestría notables. El yo es siempre odioso: en consecuencia, no hablaré de las representaciones de Mignon con la que volvieron a presentarse ante el público de Nueva York apreciables artistas a quienes conoce y quiere.

En las páginas del mismo periódico, M. Gutiérrez Nájera, esta vez sin pseudónimo, publicó la columna "Crónicas de la ópera", dedicada a hablar sobre Louise Théo y Victor Capoul ${ }^{20}$ y con ironía trae a la memoria el suceso ocurrido en Viena: "Ya, por ejemplo, no hablaré de Los cuentos de Hoffmann, que venían precedidos de tanta fama y que tan mediano éxito obtuvieron acá, a pesar del talento innegable de la señorita Derivis. Los cuentos de Hoffmann son de mal agüero. Cantándolos estaban cuando se quemó el Teatro de Viena. Yo aconsejaría a Monsieur Maurice Grau que se pusiera la señal de la cruz". Gutiérrez Nájera, M. (27 de diciembre de 1882). Crónicas de la ópera. El Nacional, pp. 1-2.

Como se ha visto, los comentarios al estreno permiten conocer las opiniones favorables y desfavorables, no sólo con respecto a ese acontecimiento, sino a la obra del propio Hoffmann. No resulta de menor interés el hecho de que, como parte de un proceso de normalización de

${ }^{20}$ Esto continúa en El Duque Job (31 de diciembre de 1882). Crónicas color de Théo. La Libertad, p. 2. 
esta ópera, en el sentido dado por Jauss (2000: 162) de un "cambio de horizonte", que incluye por supuesto el de las obras del autor alemán, ésta abandonó el recinto elitista que supuso el Gran Teatro Nacional para volverse parte del espectáculo público; suceso que es posible rastrear en los periódicos que dieron cuenta de las múltiples presentaciones de fragmentos de la obra de Offenbach ${ }^{21}$, incluyendo "La Barcarola", que, como se ha visto, no formó parte de la puesta en escena del estreno y que pasó desapercibida 22 ; en la memoria del desempeño de los cantantes $^{23}$, en las referencias a Hoffmann como músico ${ }^{24}$, en su relación

\footnotetext{
${ }^{21}$ La sociedad filarmónica francesa. (14 de abril de 1883). El Nacional, p. 3; El 18 de julio. Velada en honor de Juárez. (21 de julio de 1895). El Continental [Guadalajara], p. 1; Tomorrow Night's Concert. (8 de febrero de 1898). The Two Republics, p. 5; Artistic Concert. (8 de febrero de 1898). The Mexican Herald, p. 5; U.E. Church Concert. (10 de febrero de 1898). The Mexican Herald, p. 8; De la sociedad tapatía. (27 de octubre de 1917). El Informador [Guadalajara], p. 1; Sociales y personales. ( 22 de marzo de 1919). El Pueblo, p. 3; Tres "Espectros" que inquietaban a los vecinos, cayeron en poder de la policía. (27 de agosto de 1919). El Demócrata, p. 9; Piezas que la banda de la gendarmería del Estado ejecutará en el bosque de los eucaliptos de 11 a 1 . (26 de octubre de 1919). El Informador [Guadalajara], p. 8.
}

${ }^{22}$ Formó parte del concierto público que tuvo lugar en la Alameda de 10 a 1, bajo la dirección de Miguel Ríos Toledano: “50 'Los cuentos de Hoffman' [sic]—Barcarola y Wals [sic]-Metra”. La música de ingenieros. (14 de agosto de 1887). La Patria, p. 3.

${ }^{23}$ Sobre María Derivis: Titania (28 de octubre de 1886). Ecos de la semana. El Diario del Hogar, p. 1; Sobre el tenor Jean-Alexandre Talazac: Notas artísticas. (9 de febrero de 1893). El Correo Español, p. 2; sobre Derivis y el tenor Morie: El Reporter. (26 de abril de 1904). Por los teatros. En el Renacimiento. Diario del Hogar, p. 2; sobre el director Antonio Ribera: Los martes de El Correo. (6 de febrero de 1906). El Correo Español, p. 1. ${ }^{24}$ Sociedad Musical. La segunda audición de música de Cámara. (18 de octubre de 1907). El Popular, p. 2: “En el cuartero en 're' (op. 18, número 2) en medio de su incomparable belleza, no se destaca aún por entero su personalidad, y nótase la influencia que sobre él ejercían Haynd [sic], y sobre todo Mozart, en quien admiraba, según observa Blaze de Bury, la vigorosa magnificencia de armonía y el arte grandioso con que interpretaba las pasiones que agitaban su alma, el cual Beethoven desarrolló de modo tan maravilloso, que en sus manos la música instrumental, al decir de Hoffman [sic], se hizo la más romántica de todas las artes". // Pedrell, F. Los grandes genios musicales. Roberto Schumann. (15 de agosto de 1918). Cosmos Semanal, pp. 4-6: En esta semblanza se dice que Schumann ocultaba el nombre y lugar de nacimiento de algún amor juvenil: "Dejan sentir su influencia las obras de Juan Pablo, y no menos las de Hoffmann, no sólo como cuentista extraordinario, sino como músico de fantásticas adivinaciones" (p. 5). 
con Wagner ${ }^{25}$; asimismo cabría incluir las alusiones a personajes de la ópera, como el Dr. Milagro, que no pertenece al cuento original ${ }^{26}$. En la primera década del siglo XX, aparecen nuevamente menciones a la ópera de Offenbach y también proyectos de nuevas puestas en escena de las que el público mexicano tuvo conocimiento ${ }^{27}$; incluso de la reposición en la que ya aparecía el fragmento eliminado de la primer apuesta en escena, como se lee en Colored Wigs in Grand Opera (19 de abril de 1914). The Mexican Herald, p. 5: "At last colored wigs have been introduced into grand opera, the first being worn by Mme. Alda while playing the role of

${ }^{25}$ La juventud de Wagner. (14 de mayo de 1897). La Voz de México, p. 1: "Este periodo de labor aislada coincide en él con un impulso de exaltación alucinatoria, ya no shakespereana sino hoffmannesca, ocasionada por la asidua lectura de los escritos de Hoffmann. Muchas extravagancias se manifiestan, aun materialmente, en sus primeros ensayos de producción [...] A fin de reducir al desenfrenado joven a la razón, se necesita nada menos que la intervención del contrapuntista Weiling, organista de la iglesia de Santo Tomás de Leipzig y maestro profundo y claro de su enseñanza". // Tannhauser for the First Time in Mexico Since 1891. (24 de octubre de 1907). The Mexican Herald, p. 2: "Modern versions of the legend were made by Tieck, Heine, and Geibel, and in Swinburne's 'Laus Veneris' Tannhauser is conceived as having returned irredeemably to the Venusberg. But better known than any is the dramatic treatment by Richard Wagner in his opera 'Tannhauser', written in 1845, whose libretto follows Hoffman [sic] in identifying Tannhauser with Heinrich von Ofterdingen and introducing him into the contest of the misntrels on the Wartburg".

${ }^{26}$ En el Instituto Pasteur. Una visita del presidente Faure. (6 de marzo de 1897). La Voz de México, p. 1. El texto también se publicó en (9 de marzo de 1897). El Municipio Libre, p. 2. // Para ser hermosa. La maga electricidad. Manicuras y masajistas. (31 de julio de 1907). El Imparcial, p. 7.

${ }^{27}$ Un rival de Caruso. (27 de agosto de 1907). El Tiempo, p. 1: "Se ha asegurado el concurso de Mari Garden, de la Ópera Cómica de París, y se propone poner en escena una docena de óperas enteramente nuevas para Nueva York, entre otras, 'Thais', de Masenet y los 'Contes de Hoffman [sic]'”. // Agencia Luis A. Rivera (4 de septiembre de 1907). Gacetilla de espectáculos. El Popular, p. 3: Se menciona el elenco y el repertorio de la nueva compañía de ópera del Teatro de Manhattan, entre ella están Contes d'Hoffmann. // Por los escenarios de París. (16 de marzo de 1913). El Mundo Ilustrado, p. [16]: "La celebrada ópera cómica del inolvidable Jacques Offenbach, ha vuelto a París con la misma frescura, como si no hubiera pasado el tiempo, como si las modernas corrientes musicales, nada influyeran en los gustos del público. / Y al mismo tiempo que se veía la vieja obra en la "Gaité Lyrique" en la Ópera Cómica, subían en escenario "Los cuentos de Hoffmann" y "La Bella Elena" y "La Gran Duquesa" y casi todo el repertorio de mediados del siglo pasado" 
the Venetian courtesan Giuletta in 'The Tales of Hoffmann'".

Existen noticias de que en 1917 se intentó montar nuevamente la ópera de Offenbach en México, como está consignado en un anunció de la sección de Teatros aparecido en "Fabregas Stam. Gran compañía de Ópera Italiana". (28 de noviembre de 1917, El Pueblo, p. 5): "En ensayo: Gioconda, Sansón y Dalila, Fedora, Baile de máscaras, Cuentos de Hoffmann". La primera Sociedad Artística Mexicana Stam, formada a principios de diciembre y cuyo debut fue el 14 de ese mes en el apenas vuelto a denominar Teatro Virginia Fábregas, después de seis años de ser conocido como Teatro Mexicano, con La Gioconda, se proponía hacer una temporada de estrenos a precios módicos (Díaz-Du Pond, 2003: 151). La Compañía presentó La Gioconda, Madame Butterfly, Fausto, La Bohemia, El Trovador, Sansón y Dalila, Cavallería Rusticana, Payasos, Fedora. Noticias al respecto de sus trabajos se consignan en El Pueblo:

Han comenzado también los ensayos de la ópera "Anáhuac", del maestro Miramontes, que al subir a escena constituirá un acontecimiento sensacional por tratarse de una obra mexicana, que se presenta bajo los auspicios de mexicanos, por una compañia de primer orden. La preciosa ópera "Cuentos de Hoffmann” de Offenbach, subirá a escena a continuación. La compañía de ópera en el Virginia Fábregas. (21 de diciembre de 1917. El Pueblo, p. 10.)

La epopeya nacional mencionada, de Francisco Bracho con música del jalisciense Arnulfo Miramontes se estrenó la noche del 31 de enero y contó con la presencia del presidente Carranza (Díaz-Du Pond, 2003: 154).

El 18 de enero Stam dio la última función, los artistas italianos y mexicanos se "agruparon para trabajar por bolo en una nueva compañía: Pro Arte (Artistas Unidos) dirigida por Ignacio del Castillo y Arnulfo Miramontes. El nuevo organismo inició funciones el 22 de enero con 
Sansón y Dalila" (Díaz-Du Pond, 2003: 153). La temporada inició el 25 de mayo con Aida, el mismo día que se inauguró el Teatro Esperanza Iris con la Compañía Titular de Operetas Vienesas, aunque las críticas prefirieron la obra de Verdi (Díaz-Du Pond, 2003, 154).

Es de particular interés la nota titulada La compañía de Ópera 'Pro Arte', integrada por brillantes elementos artísticos, actuará en el cine Granat. (19 de mayo de 1918, El Pueblo, p. 11). En ella se anunció que la compañía estaba dirigida por el "maestro, director y concertador" Ignacio del Castillo, y que contaba entre su repertorio con "Cuentos de Hoffman[sic]"28; sin embargo, la noche del reestreno de Les contes d'Hoffmann nunca llegó; no hay registros de este montaje en esa década (Díaz-Du Pond, 2003, Ceballos, 2002).

Como se ha visto, el interés despertado por la ópera captó el interés del público por los escritos del alemán; un fenómeno parecido al que sucede hoy en día cuando la adaptación de una novela al cine atrae la atención hacia la obra original. Por lo que se puede colegir de los textos pertenecientes a la prensa periódica, los críticos estaban conscientes de los temas presentes en las obras de Hoffmann (el doble, el autómata, la pérdida de la voluntad, la disolución de las fronteras de la vigilia y el sueño) así como su pertenencia a un género y a una tradición; así mismo es posible comprobar que dichos elementos llegaron a un público más general por medio de la ópera, para constituir así un imaginario colectivo en torno a Hoffman y su obra ${ }^{29}$. La gente quizá no lo había leído, pero en la ópera podía encontrar su sombra. La ópera creó un doble de Hoffmann, un mito que, a diferencia del protagonista de Las aventuras de la noche de San Silvestre, se refleja en todos y cada uno de los personajes.

\footnotetext{
${ }^{28}$ La compañía de Ópera "Pro Arte", integrada por brillantes elementos artísticos, actuará en el cine Granat. (19 de mayo de 1918). El Pueblo, p. [11].

${ }^{29}$ Un ejemplo curioso es la asimilación de Hoffmann a la recepción de Poe, como lo demuestra: Un triunfo sobre la muerte. (4 de junio de 1913). Alrededor del Mundo, p. 9: "[El actor] Perier se caracteriza de la muerte y actúa en una historia sobre los cuentos de Hoffman, el Edgar Poe de Alemania".
} 


\section{REFERENCIAS BIBLIOGRÁFICAS}

BIDAULT DE LA CALLE, S. (2002). "Belle Époque y frivolidad: El difícil paso de la conciencia decimonónica a la modernidad”. En $L a$ Danza en México. Visiones de cinco siglos. Vol. I, M. Ramos Smith y P. Cardona Lang (dirs.), 595-611 México: Conaculta, INBA, Escenología A.C.

CASTEX, P-G. (1962). Le conte fantastique en France. De Nodier à Maupassant (1. a ed.: 1951). París: José Corti.

CEBAllos, E. (2002). La ópera (1901-1925). México: Conaculta, Escenología A.C.

DÍAZ DU-POND, C. y CEBALLOS, E. (2003). 100 años de ópera en México. México: INBA; Escenología A.C.

GONZÁLEZ MARTÍNEZ, J. M. (2006). "Literatura y música. Fundamentos teóricos de la transposición”. Revista de Musicología XXIX. 1, 164-189.

(2009). "Factores condicionantes en la trasposición literaturamúsica". Anuario musical 64, 259-278.

JAUSS, H. R. (2000). La historia de la literatura como provocación (1. ${ }^{\mathrm{a}}$ ed.: 1967) Barcelona: Península.

MAÑón, M. (2009). Historia del Viejo Gran Teatro Nacional de México (1841-1901). T. 2. México: Conaculta, INBA.

OLAVARRÍA Y FERRARI, E. de (1961). Reseña histórica del teatro en México. 1538-1911. T. II. Prólogo de Salvador Novo. México: Porrúa.

PAHLEN, K. (1980). "Introducción". En Los cuentos de Hoffmann. Libreto francés-castellano, J. Offenbach. Intr. y comentarios de Kurt Pahlen con la colaboración de Rosemarie Köning. Buenos Aires: Javier Vergara Editor.

PEREZ GIL, V. (1993). El relato fantástico desde el romanticismo al realismo. Estudio comparado de textos alemanes y franceses. Tesis 
doctoral. Madrid: Universidad Complutense de Madrid.

RAMOS SMITH, M. (2013). Teatro, música y danza en el México de la Bella Époque (1867-1910) (1. ${ }^{\mathrm{a}}$ ed.: 1995). Prólogo de José Emilio Pacheco. México: Escenología A.C.

REYES DE LA MAZA, L. (1964). El teatro en México durante el Porfirismo (1880-1997). T. I. México: Imprenta Universitaria.

ROAS, D. (2002). Hoffman en España. Recepción e influencias. Madrid: Biblioteca Nueva.

SPOELBERCH DE LOVENJOU, Ch. de (1968). Histoire des Cuvres de Théophile Gautier. Ginebra: Slatkine Reprints.

SOSA, O. (2004). 70 años de ópera en el Palacio de Bellas Artes. México: INBA. (2010). La ópera en México de la Independencia al inicio de la Revolución (1821-1910). México: INBA.

TEICHMANN, E. (1961). La fortune d'Hoffmann en France. París: Genf.

Recibido el 20 de abril de 2018.

Aceptado el 24 de julio de 2018. 